\title{
José Mariano Mociño. El destino de su obra y las cartas a De Candolle
}

\author{
Miguel Fuertes Olavide, Carlos Martinez Shaw * \\ Y Miguel Ángel Puig-Samper Mulero
}

\begin{abstract}
RESUMEN ABSTRACT
En este artículo se presentan cuatro cartas que dirigió el botánico José Mariano Mociño (1757-1820), miembro destacado de la Real Expedición Botánica a Nueva España (17871803), durante su exilio en Francia al botánico suizo Agustín Pyramus De Candolle. Las cartas precisan la cronología del exilio de Mociño, muestran relaciones con otros afrancesados exiliados y confirman las relaciones entre los dos botánicos y su importancia en la conservación.

Four letters forwarded by botanist José Mariano Mociño (1757-1820), a distinguished member of the Royal Botanical Expedition to New Spain (1787-1803), are presented in this article. The letters, written during Mociño's exile in Franced to the Swiss botanist Agustin Pyramus De Candolle, specify the chronology of the exile, account of Mociño's contacts with other "afrancesados" in exile, and confirm the relationship between both botanists, as well as its importance for the conservation of documents regarding the expedition.
\end{abstract}

La Real Expedición Botánica a Nueva España, REBNE, fue una de las más complejas entre las muchas que organizó la Corona española durante el siglo XVIII, por la duración, por la extensión de sus recorridos y por la extraordinaria calidad y cantidad de los materiales que se reunieron. La botánica, durante la llustración, atrajo gran cantidad de estudios por los abun-

* UNED. 
dantes usos de muchas plantas: agrícolas, medicinales, tintóreas, textiles, maderables, etc. Su estudio sintonizaba con los propósitos reformistas como muestra de la renovada confianza en la razón y por eso su conocimiento formó parte de la ofensiva para superar el atraso del país ${ }^{1}$. Este interés dio pie a la organización de muchas expediciones con fines naturalistas, como las famosas destinadas a Chile y Perú, dirigida por Ruiz y Pavón (1777-1788), y a Nueva Granada, dirigida por Mutis (1783-1808) ${ }^{2}$.

\section{LA REAL EXPEDICIÓN BOTÁNICA A NUEVA ESPAÑA 1787-1803}

El objetivo de la REBNE fue recolectar y describir las plantas propias de Nueva España, confeccionando herbarios y realizando dibujos. Del material se hicieron duplicados, tanto por seguridad como para proveer dos colecciones, una para México y otra para Madrid adonde, además, se enviaron plantas vivas y semillas. En octubre de 1787 comenzaron las primeras excursiones científicas a las inmediaciones de la capital mexicana para herborizar, y continuaron cada vez con un carácter más general y sistemático. Durante 1789 en una nueva salida se llegó a la costa del Pacífico a la altura de Acapulco. En la tercera y más compleja de las exploraciones, que se inició el 17 de mayo de 1790, los expedicionarios se dirigieron hacia el norte y dividieron los efectivos al llegar a Mazatlán. Un grupo realizó un recorrido más largo, llegando a Chihuahua y regresando luego hacia el sur, hasta Aguascalientes, donde se encontraron con el segundo grupo, cayo itinerario, más corto, les llevó por las provincias de Sinaloa y Ostimuri. Los resultados botánicos de las tres primeras salidas han sido estudiados por Álvarez López y McVaugh ${ }^{3}$. Al finalizar esta tercera salida hubo una considerable dispersión.

\footnotetext{
Martínez Shaw, C., El Siglo de las Luces. Las bases intelectuales del reformismo, Madrid, 1996, pp. 70-76

2 Sanchez, B.; Puig-Samper, M.A. y de la Sota, J., La Real Expedición Botánica a Nueva España, Madrid, 1987, pp. 297-98. En el libro, editado con motivo de la Exposición celebrada en el Jardín Botánico de Madrid sobre la REBNE, se enumeran más de 60 expediciones, sin contar que en muchas otras de diferentes fines fue frecuente la recogida de muestras y especimenes

3 Álvarez lopez, E., "Las tres primeras campañas de la expedición científica dirigida por Sessé, y sus resultados botánicos", Anales del Inst. Bot. Cavanilles, t. XI, vol. I, Madrid (1952), pp. 1-103.

- "Noticias y papeles de la expedición científica mejicana dirigida por Sessé", Anales del Inst. Bot. Cavanilles, t. X, v. II (1951), pp. 1-79.

- "Notas sobre la expedición científica mejicana dirigida por Sessé. Algunas cuestiones de sinonimia y prioridad botánica", Bol. Soc. Esp. de Hist. Natural. t. XLVIII (1950), pp. 259-274.

MCVAUGH, R., "Botanical results of the Sessé \& Mociño Expedition (1787-1803): VI. Reports and records from western Mexico, 1790-1792", Boletín del Instituto de Botánica, Época 3, vol. I, núm. I, Universidad de Guadalajara, México (1998).
} 
Algunos miembros permanecieron en México, otros llegaron hasta la costa de Canadá donde trabajaron durante los años 1792-93, y entre tanto otro expedicionario, José Longinos Martínez, recorría a fondo California ${ }^{4}$.

La siguiente campaña, iniciada en abril de 1793, se llevó a cabo, de nuevo, dividiendo los efectivos. Mientras un grupo exploraba diversas zonas de la Huasteca, al este de la capital mexicana, hasta la costa, otro se dirigió hacia la Mixteca y el istmo de Tehuantepec, reuniéndose los dos grupos en el camino de regreso. A primeros de 1795 todos los expedicionarios estaban en la capital mexicana. Se habia rebasado el plazo inicial concedido a la REBNE, que expiraba en junio de 1794, pero gracias a una prórroga sus actividades se extendieron hasta 1803, año de su regreso a Madrid, formando dos comisiones, una a Guatemala, y otra, a Cuba, Puerto Rico y Santo Domingo ${ }^{5}$.

Un importante objetivo de la REBNE fue la creación del Jardín Botánico de México, uno de los primeros en América, inaugurado el primero de mayo de 1788. Desde su cátedra se pretendía una reorganización de los estudios botánicos ${ }^{6}$, incorporando las ideas sistemáticas de Linneo ${ }^{7}$. Su localización y realización material tropezaron con inconvenientes, ya que el talante innovador que representaba la empresa motivó alguna reticencia por parte de las autoridades académicas novohispanas, recelosas de actividades que se desarrollaban al margen de su influencia directa ${ }^{8}$ y con el motivo añadido del nombramiento de algunos de sus miembros Alcaldes Examinadores del Protomedicato de Nueva España y Visitadores de boticas, lo que suponía dotarles de una capacidad inspectora con la que se trató de mejorar el prestigio, bastante deteriorado, de aquella institución.

\section{a) Los miembros de la REBNE}

Martín Sessé Lacasta, su director, nacido en Jaca en 1751, tras cursar estudios de medicina en Zaragoza ${ }^{9}$, prestó servicios en el ejército. Entre

\footnotetext{
4 Maldonado Polo, J.L.. De California a El Petén, El naturalista riojano José Longinos Martinez en Nueva España, Instituto de Estudios Riojanos, Logroño, 1997.

5 Blanco, P.; Pulg-Samper, M.A.; Zamudio, G.; Valero, M., y Maldonadoo, J.L., La exploración de las Islas de Barlovento, Aranjuez, 1999.

6 Arias Divito, J.C., Las expediciones cientificas españolas del siglo xvili, Madrid (1968), pp. 87-97. MALDONADO POLO, J.L., "La institucionalización de la Historia Natural en Nueva España. El modelo de trasplante de la ciencia metropolitana a ultramar", en De la Ciencia ilustrada a la ciencia romántica. Aranjuez, 1995, pp. 411-426

Puig-SAMPer, M.A., "La enseñanza de la botánica en la España llustrada", en La Real Expedición..., pp. 59-78.

8 Puerto Sarmiengo, F.J., La ilusión quebrada. Madrid, 1988, pp. 111-113.

9 Martinez Tejero, $V$., "Notas sobre la actividad médica de Martín de Sessé", Homenaje a Martin de Sessé y Juan del Castillo, Huesca, 1993, pp. 13-16.
} 
1780 y 1785 vivió en Cuba y mantuvo correspondencia con Gómez Ortega, director del Real Jardín Botánico de Madrid, BJBM. El mismo año de su traslado a México, 1785 , fue nombrado corresponsal ${ }^{10}$, dedicándose de Ileno, una vez en la capital de Nueva España, a la organización de la Expedición.

Jaime Senseve, farmacéutico español establecido en México, quizá el menos sobresaliente de los participantes, fue el primer expedicionario en recibir su nombramiento. Acompañó a Sessé en las primeras recolecciones de plantas, antes de la llegada de José Longinos Martínez, cirujano, especialista en zoología y anatomía, y de Vicente Cervantes, un notable botánico que poseía grandes dotes como organizador. Ambos fueron elegidos por Gómez Ortega por su brillante participación en los cursos del BJBM de $1786{ }^{11}$. Desde Puerto Rico se incorporó Juan Diego del Castillo, que había sido director de la Botica del Hospital de Puerto Rico, donde había vivido en los 15 años previos a su incorporación a la REBNE.

Atanasio Echeverría y Vicente de la Cerda, dibujantes, fueron nombrados a propuesta de Sessé, procedentes de la Academia de Bellas Artes de San Carlos de México. Echeverría tuvo una participación más activa, estuvo en Nutka y posteriormente acompañó al grupo de Sessé a Cuba, donde pasó a trabajar en la otra expedición que tenía lugar por entonces en la isla, la del conde de Mopox ${ }^{12}$. En 1803 vino a España trabajando en completar las láminas, mientras de la Cerda quedaba en México.

Los mexicanos José Maldonado y José Mariano Mociño, en quien se centra este trabajo, comenzaron como discipulos, estuvieron entre los primeros de la Cátedra de botánica, antes de ser plenamente incorporados a la REBNE, aunque no sin tener que salvar algunos obstáculos.

\section{b) José Mariano Mociño. Sus aportaciones a la REBNE}

José Mariano Mociño contribuyó tan decisivamente a la REBNE que comúnmente se conoce a esta expedición como de Sessé y Mociño y el apellido de ambos botánicos figura en las denominaciones oficiales de los

\footnotetext{
io Archivo Real Jardin Botanico Madrid (ARJBM). V, 1,1,2. Copia del titulo de corresponsal concedido a Sessé por el RJBM.

11 Puig-Samper, M.A., "Exercicios públicos de Botánica realizados en el Jardín Botánico de Madrid", en La Real Expedición..., p. 73.

Lozoya, X., Plantas y luces en México. La Real Expedición Botánica a Nueva España 17871803, Barcelona, 1984, pp. 39-45. Higueras, B. (ed.), Cuba llustrada. La Comisión Real a Guantánamo. Barcelona, 1991.
} 
abundantes géneros y especies de plantas cuya descripción se hizo por primera vez basándose en ejemplares recogidos por los expedicionarios. El Indez Kewensis o el Gray Herbarium Card Index, que son referencia para el reconocimiento internacional de las denominaciones botánicas, ofrecen abundantes ejemplos.

Mociño nació en el Real de Minas de Temastecaltepec en septiembre de 1757, en 1776 se graduó de Bachiller en Artes y en los años 1777 y 1778 fue estudiante de Teología, pero abandonó la carrera eclesiástica. Se casó en 1778 y se trasladó a vivir a Oaxaca. En 1784 abandonó a su familia y se instaló en la capital mexicana ${ }^{13}$. La separación de su mujer originó pleitos que fueron, a lo largo de su vida, motivo de problemas judiciales y económicos. Entre 1784 y 1787 siguió estudios de Medicina y, simultáneamente, de Matemáticas, y en 1789 se inscribió en el curso de Botánica que se impartía por vez primera en México y dictaba Vicente Cervantes ${ }^{14}$. Debió destacar, ya que fue uno de los elegidos para actuar en los ejercicios de fin de curso ${ }^{15}$, y ese mismo año fue propuesto por Sessé para incorporarle a la expedición, tomando parte en la tercera salida. La decisión implicaba que Senseve no participara y, de esa forma, con lo ahorrado en dietas, podría pagarse un sueldo a Mociño; al parecer el de Maldonado, que también se incluyó, se obtuvo del presupuesto general. Todos estaban de acuerdo en lo que atañia a Senseve (menos el interesado y su mujer, que, en España, se ocupó de que fueran restituidos los derechos de su marido), pero, Longinos, que no aceptaba de buen grado la autoridad de Sessé, se opuso a la elección de Mociño y defendió que fuera Mariano Aznares el beneficiado. Como consecuencia de las tensiones, Longinos tampoco acompañó a los expedicionarios. Sessé respondió con un informe al virrey indicando que a Longinos tampoco deberían pagárseles las dietas que correspondian a los expedicionarios mientras estaban en campaña, arremetiendo además contra su capacidad profesional ${ }^{16}$.

"Longinos no se halla con capacidad para escribir ninguna especie de obra, aunque sea en idioma vulgar. Carece de instrucción e inteligencia de los autores maestros, cuyas huellas es forzoso seguir para caminar con acierto; le falta estilo y carece de ortografia. En México ha podido encubrir

\footnotetext{
13 Lozoya, X., Plantas y luces..., p. 42.

14 Archivo Real Academia Medicina (ARAM). Carpeta 65, Certificados de méritos académicos de J.M. Mociño.

15 ARJBM, V, 1,3,1. Carta de Vicente Cervantes al Virrey, México. 8-11-1789 (Comunicando la celebración de los ejercicios y la intervención en el acto académico de José Moziño, médico aprobado, Justo Pastor Torres, practicante de farmacia y José Maldonado, practicante de cirujia...).

16 Archivo Museo Nacional Ciencias Naturales (AMNCN). Informe de Sessé al Virrey, Zapotlán. 13-2-1791.
} 
esta escasez de elementos tan necesarios para ingerirse en cualquiera ciencia, valiéndose de su compañero y mi condiscípulo D. Mariano Aznares, monstruo de ingratitud, que olvidado de los mayores beneficios y convirtiéndolos en injustos resentimientos porque no hice la injusticia de proponerlo en lugar de Senseve sin haber saludado la Botánica, y con agravio de los que ya habían dado públicas muestras de su adelantamiento en ella, fomentó la insurrección de Longinos, cooperó al proyecto del Gabinete, en que olvidado de su principal obligación, se distrajo la mitad del año 89 y todo el $90 \ldots$

No me explicaría con una verdad tan desnuda, que podría reputarse por calumnia, si cada una de sus cartas, y oficios originales, que corren en el expediente de nuestras desavenencias no fuera un testimonio que la calificara con evidencia; y si no conociera que cualquier disimulo en este lance viene a ceder en perjuicio del Real servicio.»

Sessé comunicó también al ministro Porlier ${ }^{17}$ que Longinos, considerándose independiente, "...verosímilmente remitiría sus trabajos por separado", y en otro informe a Revillagigedo que, en una relación de aves, "...me ha parecido hallarse equivocadas muchas en género y especie», y pedía que el trabajo de Longinos fuera revisado por expertos, ya que no quería avalarlo.

Longinos organizó por su cuenta, en la capital mexicana, un Gabinete de Historia Natural y posteriormente emprendió una exploración por la Alta y la Baja California durante cerca de tres años, prácticamente en solitario y sin coordinación con el resto de los trabajos. Entre catálogos, diarios y descripciones reunió cinco tomos ${ }^{18}$, y más de treinta cajones de diversos materiales. Por decisión real Senseve fue restituido en su puesto ${ }^{19} \mathrm{y}$ los nombramientos de Mociño y Maldonado desautorizados. La orden llegó el 22 de marzo de 1791, cuando los expedicionarios ya estaban en campaña, por lo que no fue aplicada. El virrey dio instrucciones para que Mociño, Echeverría y Maldonado abandonasen la REBNE incorporándose a la Expedición de Límites de Francisco de la Bodega, que se alistaba para partir desde San Blas de Nayarit hacia Nutka. La demanda de naturalistas para la expedición de límites permitió al virrey solucionar varios problemas a la vez: la marcha de Mociño, que recibiría un salario con cargo a la Expedición de Límites, permitía a éste hacer frente a las reclamaciones de su mujer, mientras Senseve era restituido en sus derechos y la REBNE ampliaba el área de su actividad.

\footnotetext{
17 ARAM. Serie documental 66. Carta de Sessé a Porlier. 28-5-1790 y al virrey Revillagigedo 20-6-1790.

is Maldonado Polo, J.L., Flora de Guatemala, Madrid (1996), p. 45. Remite a Archivo GeneRAL DE LA NACIÓN de México (AGN), Historia-527. "Representación de Longinos a Revillagigedo", 26-6-1794.

19 AMNCN. Carta del Virrey a! Ministro 1-7-1790, y respuesta: Real Orden 22-3-1791.
} 
Las actividades en Nutka se prolongaron hasta febrero de 1793. Mociño realizó el trabajo propio de un naturalista y en el apéndice final del diario de a bordo de Francisco de la Bodega figura un Catálogo de los animales y plantas que han reconocido y determinado según el sistema de Linneo los facultativos de mi expedición don José Mociño y don José Maldonado ${ }^{20}$. Mociño aprendió la lengua de los indígenas actuando como intérprete en los interrogatorios de Francisco de la Bodega al jefe Macuina y dejó un diccionario de la lengua de los nativos que constituye una lista de 440 términos del que se conserva varias copias y se complementa con otros, como el editado por Alcalá Galiano en 1802, al cual algunos suponen también obra de Mociño ${ }^{21}$. Maldonado, que ejerció como cirujano en uno de los bosques llegó hasta la bahía de Bucarelli ${ }^{22}$, a los $55^{\circ}$ de latitud, en la costa de Alaska y a su regreso abandonó la REBNE.

Poco después de su regreso, Mociño, en compañia de Echeverría, participó en una nueva campaña hacia el sudeste de México que se prolongó hasta comienzos de 1795, herborizando en la costa, entre Tehuantepec y Tabasco, y realizó numerosos envíos a México. En el ínterin llegó la noticia del fallecimiento de Castillo y Mociño obtuvo finalmente nombramiento oficial, que se hizo efectivo el 16 de septiembre de 1794, al ocupar su vacante. En el curso de esta campaña ascendió al volcán de Tuxla al menos en tres ocasiones entre septiembre y diciembre de 1793. Su informe para las autoridades locales se acompañó de una lámina de mano de Echeverría que muestra el volcán en erupción. El texto fue redactado en estos términos ${ }^{23}$ :

"Al regresarme de Acaquecam la semana pasada divisé desde una de las dehesas de Corral Nuevo la corona del volcán de Tuxtla cubierta de blanco; cosa que extrañó muchísimo por no haberlo dejado asi ocho días antes que lo habia perdido de vista.

20 San Pio Aladren, M.P., "El diario de 1792 de Juan Francisco de la Bodega y Quadra", en Las cuituras de la costa Noroeste de América, Madrid (1989), pp. 291-298. Bernabeu AlBert, S., Juan Francisco de la Bodega y Quadra. El descubrimiento del fin del mundo (1775-1792), Madrid (1990), pp. 222-237. (La relación de animales y plantas figura también en la mayoria de las obras dedicadas a la REBNE.)

21 Monge, F., y Olmo, M. Del, Las "Noticias de Nutka" de José Mariano Mociño. Madrid (1999). (Recoge información del libro Las Noticias de Nutka que se publicó en México en 1813 y de manuscritos del Archivo del Museo Naval (AMN). Ms. 468 del folio 114 al 161 con el título Descripción de la isla de Mazarredo, con indicación de ser copia de la obra de Mociño y en el Archivo del Ministerio de Asuntos Exteriores (AMAAEE). Mss. 145, 146, que figuran con la advertencia final "es copia hecha en México 12 de abril de 1793. Antonio Bonilla".

22 AMAAEE. Ms. 10. Diario del año 1792 del comandante Francisco Caamaño, p. 22. “El botánico José Maldonado, que conduje para inspección de las producciones de estos países y acompanó para mejor desempeño de su cargo a reconocimiento a puerto, encontró los siguientes: Animales terrestres y aquáticos, quadrúpedos, peces, moluscos y plantas". Sigue un listado de especies.

23 ARAM. Legajo 10. Serie documental 66, 638. Informe elaborado por Mociño. 
Luego que llegué a este pueblo vinieron varias personas a comunicarme la novedad de estar el volcán cubierto de nieve, opinión en que insistian, sin embargo de haberles significado yo la suma dificultad que me costaba creerlo tanto por conocer la poca elevación de la montaña sobre el nivel del mar cuanto por que ningún día llegó el termómetro a indicarme un grado de frío que hiciera recelar una nevada en los montes.

Pero para cerciorarme de la realidad subí a la cumbre el 23 de éste a las dos de la tarde soplando el viento por el sur y hallé que unas concreciones salinas que han encostrado la montaña en más de tres leguas de circunferencia habia sido lo que parecía nieve a los que la veían desde lejos y sentían el frío regular de la estación que en estos paises extraña mucho por ser cálido su temperamento.

Esta costra es muy delgada, y por tanto no pude recoger sola su sustancia, sino mezclada con la arena volcánica que estaba debajo en cuyo estado la llevo a esa capital, para que separada por medio de la solución se reconozca bien su naturaleza. Yo le he encontrado sabor ácido punzante, y puesta al fuego no hizo crepitación ninguna ni se fundió.

Todos los sitios en que en la parte salía humo, o vapor en mi segundo viaje, carecían ahora de él pero alli mismo advertí una multitud de circunferencias de círculo formadas como con gis (¿gas?) sobre la arena y escorias, dentro de las cuales se me quemaba la mano al hacer unas pequeñas excavaciones siendo muy remiso el calor que sentía fuera de ellas, aun introduciendo los dedos a mayor profundidad. La materia de que están formadas estas curvas circulares es puntualmente la misma que ha hecho la incrustación.

Bajé con ingentísimo trabajo a una de las calderas que hacian las erupciones más impetuosas en mi primer viaje y ahora solamente humea y conserva en muchas partes piedras convertidas en ascuas, encontré diversidad de grietas, cuya dirección es bastante tortuosa como a más de la vista me lo acreditaba una vara flexible que iba introduciendo por ellas.

Una parte de la peñasquería que por la banda sur está más inmediata al mar se ha desplomado ya después de mi segunda inspección y recelo que la restante no tarde muchos meses en hundirse. Cuando esto suceda no amenaza el menor peligro ni a las poblaciones ni a los sembrados, y estoy persuadido que tampoco recibirían daño aun cuando se hundiese toda la montaña que por la parte que ve a estos pueblos, me parece que tiene consistencia para algunos siglos, si una de las extraordinarias convulsiones de nuestro Globo no trastorna el estado actual de las cosas.

Dios guarde a V.E. muchos años. San Andrés de Tuxla. Diciembre 27 de 1793.»

Al prorrogarse la expedición Mociño marchó a Guatemala, donde realizaría en solitario su Flora de Guatemala, que incluye 526 especies. Sin embargo, al saber que le acompañaría Longinos quiso ser relevado ${ }^{24}$ :

24 Maldonado Polo, J.L., Flora de Guatemala.., pp. 68, 77-80 y 141-142. 


\begin{abstract}
"Me veo en la precisión de suplicar a V.E. se digne redimirme de esta desgracia, si puede llamarse asi a la sociedad con un hombre, con quien ninguno de la Expedición ha podido y quier subsistir... No cabe la menor duda de que mi ingreso a este cuerpo es uno de los más fuertes estímulos para la injusta aversión que este sujeto, a quien jamás he ofendido...”
\end{abstract}

Mociño y Longinos partieron por separado, pero llevaron a buen fin la Comisión a pesar de los antecedentes y de sufrir adversidades, terremotos y la erupción del volcán Quetzaltepeque, que provocaron la pérdida de gran cantidad de materiales. El propio Mociño en el prefacio de su Flora dice:

\footnotetext{
“Hemos examinado el Reino de Guatemala (...). También conservamos las flores naturales en alcohol, las cuales, para nuestro inmenso pesar, desaparecieron al derrumbarse nuestra casa como consecuencia de la destrucción de San Salvador, permaneciendo así sepultadas bajo las ruinas de la desdichada ciudad junto con no poco de nuestra escasa fortuna.»
}

La ayuda de un grupo de ilustrados que habían fundado en octubre de 1795 la Real Sociedad Económica de Amantes de la Patria de Guatemala fue decisiva. Su principal impulsor, Jacobo Villaurrutia, era oidor de la Audiencia, y volverá a ayudar a Mociño en los últimos días de nuestro botánico. El arquitecto Pedro Garciaguirre publicaba la Gazeta de Guatemala, gracias a la cual se conservan noticias de las actividades de la Comisión, asi como del Gabinete de Historia Natural que Longinos organizó, con la colaboración del Capitán General D. José Domás y Valle y de la Sociedad de Amigos, que adquirió los locales y nombró a Longinos socio de mérito. La Sociedad colaboró también, tratando de aprovechar la orden de Carlos IV de 28 de junio de 1797, que suprimía trabas comerciales, en la promoción de estudios llevados a cabo por los expedicionarios sobre el hule y el salitre y sobre el añil, tinte vegetal que tenía para Guatemala gran importancia económica, y acerca del cual Mociño trabajó reiteradamente.

En diciembre de 1797 Sessé, desde La Habana, comunicó la orden de regresar a México. Longinos se mostró remiso, pero ante la insistencia de las autoridades inició el viaje, que no concluyó; a su paso por Yucatán su estado de salud se agravó y murió en Campeche en noviembre de $1802{ }^{25}$. Mociño también demoró el regreso, pasando por Huehuetenango y Chiapas, donde, a instancias del obispo José Fermín Fuero, se ocupó, entre junio y octubre de 1798 , de problemas sanitarios y mineralógicos para identificar el contenido de mercurio en unas vetas de cinabrio. Contó para

25 Lozoya, X., Plantas y luces..., pp. 162-163. 
su demora con permiso del nuevo virrey, Miguel Antonio Azanza ${ }^{26}$. Finalmente llegó a Ciudad de México, el 5 de febrero de 1799. Los materiales reunidos en Guatemala habían llegado previamente, traídos por el dibujante Vicente de la Cerda.

\section{c) Mociño, desde la llegada a España hasta su exilio}

La REBNE comenzó los preparativos para trasladarse a España en 1802. Sessé y Senseve hicieron escala en La Habana para recoger algunas pertenencias. Mociño, tras haber estado retenido por los pleitos de su separación, llegó a Cádiz el 31 de julio de 1803. Al saber que Sessé aún no había llegado recurrió a Cavanilles, director de RJBM, en los siguientes términos ${ }^{27}$ :

“Muy Señor mío y de todo mi respeto, informado por D. Fermín de Sessé de la benigna acogida que $V$. prepara a los que con el título de botánicos hemos viajado de orden de S. M. por las provincias de su dominación en la América Septentrional; le participo a V. mi llegada a este puerto con el desconsuelo de haber sabido por el correo de ayer, que aun no estaba en esa corte el Director de nuestra expedición D. Martín de Sessé, que es puntualmente quien trae los herbarios, dibujos, manuscritos y demás cosas de nuestra colección, como también el finiquito de nuestras cuentas en las cajas reales de Nueva España; documento sin el cual no juzgo fácil, que se me abonen aquí los sueldos vencidos, ni se me costee el viaje a Madrid como se me ha costeado por la real hacienda el que hice de México a Veracruz y el de Veracruz a Cádiz.

No sé que recurso interponga en este caso ni juzgo que deba interponer alguno sin previa orden y consejo de $\mathrm{V}$. Soy aqui un extranjero sin relaciones algunas, he venido de orden y a expensas del Rey a concluir los trabajos botánicos, en que tengo una parte más ruda, y la más pequeña, y estos títulos me animan, $y$ hacen confiar, que aunque por justos motivos se halla ausente todavía el Director de la expedición en que soy individuo, no me faltará la protección del primero de los profesores de esta ciencia a quien venero como jefe mío.

Como tal sírvase $V$. imponerme los preceptos de su agrado, pues me sería de mucha satisfacción el poderle acreditar que soy su súbdito y atento servidor."

Gracias a Cavanilles, Mociño llegó a Madrid, donde poco después se le unió Sessé. Comienzan ahora las gestiones para disponer de un local

26 Sobre las relaciones de Mociño y Azanza véase la primera de las cartas de Mociño a De Candolle en el último apartado de este trabajo.

27 ARAM. Serie documental 63. leg. 13C. Carta de Mociño a Cavanilles. Cádiz 16-8-1803. 
donde reunir los materiales de la expedición, que se encontraban dispersos, algunos almacenados provisionalmente en la oficina de Ruiz y Pavón, de donde hubieron de reclamarlos. Una carta de Sessé al ministro Caballero es muy elocuente ${ }^{28}$ :

“En la colección de plantas y dibujos de la Expedición Botánica a Nueva España que se entregó a los autores de la Flora Peruana, echo de menos dos tomos de manuscritos, dos paquetes de herbario y multitud de dibujos de plantas y animales que remití al ministerio desde Guadalajara el año de 1791.”

Sessé y Mociño tratan de abrirse camino en la vida científica madrileña: inician una campaña para reformar la enseñanza de la Medicina en México ${ }^{29}$ y presentan un remedio contra las fiebres, el Colpachi, que competía con la quina y cuyos ensayos clínicos se llevan a cabo en El Escorial ${ }^{30}$. Sessé, en 1804, opta a la plaza de director del Botánico vacante por la muerte de Cavanilles, pero es adjudicada a Zea ${ }^{31}$. Entre finales de 1804 y comienzos de 1805 , durante la epidemia de fiebre amarilla ${ }^{32}$, Mociño ejerce como médico en Écija. En 1805, muere Senseve, al tiempo que Mociño ingresa en la Academia de Medicina, lo que no alivia sus dificultades materiales. A los expedicionarios se les adeudan en algún momento sueldos de nueve meses y Mociño, ante la falta de recursos, vive en casa de Sessé. En 1806 presentó un informe sobre la "connaturalización en España del añilss ${ }^{33}$. Sólo 10 días después de los acontecimientos del Dos de Mayo de

28 AMNCN. Carta de Sessé al ministro Caballero de 10-1-1804.

29 ARAN. leg. 19. 1137. Carta de Antonio Porcel a Ignacio Maria de Luzuriaga en relación con una representación de Martin de Sessé y José Mocin̄o, sobre la mala calidad de la enseñanza de la medicina en la Universidad de México, 10-11-1804.

30 ARAM. Carpeta archivo 20. Papeles diversos años 1793-1841. Varias cuartillas con anotaciones de Sessé sobre el uso del Colpaxi en el Hospital del Real Sitio de San Lorenzo.

31 Soto, D., Francisco Antonio Zea, Aranjuez, 1999. Sobre este destacado botánico, que fue colaborador de Mutis, volveremos a referirnos al revisar la correspondencia de Mociño con De Candolle.

3e ARJBM. Cartas. div. V. desde 1,5,12: Informe sobre la fiebre amarilla del 30-9-1804, hasta 1,5,29: carta de Riquelme a Mociño en la que le comunica medidas para realizar la desinfección. Hay en total 17 cartas e informes que dan idea de una intensa actividad y nos muestran a un Mociño atento a las últimas novedades, ya que maneja copia de un informe sobre la fiebre amarilla de Deveze a Miffin, gobernador de Pennsylvania de 27 de agosto de 1797.

ARAM. leg. 19. 1146. Carta de Juan Bautista Payba y Saravia a Mociño informándole de varios casos que ha atendido. Écija 19-12-1804.

ARAM. Carta de José Rodríguez Romano a Mocin̄o informándole de la utilización de agua carbónica en tres enfermos de fiebre amarilla, con comentarios sobre uso, dosis y evolución de los enfermos, Éciija. 14-12-1804.

33 ARJBM. V, 1,5,31.

ARAM. leg. 22. 1315. Carta de Mociño a Antonio Porcel, en relación con las correcciones del Tratado de Xiliquite o añil de Guatemala. 16-10-1806. (Se queja Mociño de los muchos errores de impresión.) 
1808, Mociño sustituyó a José Martínez San Martín, que se había incorporado a la guerrilla, como Secretario de la Academia de Medicina, alineándose como afrancesado, lo que condicionará peripecias posteriores. Ese mismo año realiza un dictamen sobre las aguas medicinales de Solán de Cabras ${ }^{34}$. El desenlace de la REBNE se complicó por los acontecimientos políticos y militares, pero sobre todo por la muerte de Sessé, ocurrida el 4 de octubre de 1808. Poco después Echeverría intenta marchar a México y Mociño se dirige al ministro Pedro Ceballos explicándole la precaria situación. Hará todavía varios intentos para conseguir un local adecuado para los materiales y documentos de la REBNE ${ }^{35}$. Consigue que se le eximan de algunos gravámenes e impuestos ${ }^{36}$. Su discípulo Pablo de la Llave ${ }^{37}$ le presta alguna ayuda. Entretanto es nombrado vicedirector de la Academia de Medicina. El Gobierno de José Bonaparte estaba interesado en que las instituciones normalizaran su funcionamiento, pero de la escasa respuesta que encontró son buen ejemplo las diversas cartas que recibe Mociño de sus consocios excusando su asistencia, como la que reproducimos de José Pavón, pretextando la muerte de su suegro ${ }^{38}$

"Mi cordial amigo y consocio. La continua asistencia que he tenido de la enfermedad de mi padre político, de la cual ha muerto, me ha privado de asistir a las sesiones académicas. La muerte de este padre benefactor mío me obliga a asistir a la madre política, viuda y acompañarla; estoy sumamente ocupado en asuntos de cuentas y entierro, aniversario y otros intereses que debo esclarecer en beneficio de mi consorte e hijo quienes son herederos.

Baxo estos presupuestos no puedo asistir en algunas sesiones a la Academia que siempre he procurado asistir sin interrupción para aprender de tan ilustre asamblea.

34 ARAM. leg. 23. 1407. Dictamen de Mociño sobre observaciones de progresos de las aguas medicinales de Solán de Cabras. 8-6-1808.

35 ARAM. leg. 13. 736 y 737. Borrador del discurso (pronunciado por Mociño) sobre la utilidad de constituir un centro para la conservación de las producciones naturales. $Y$ discurso sobre comienzo de las clases de zoología en el Gabinete de Historia Natural (insiste en la utilidad de un centro para la conservación de las producciones naturales). Pese a no estar fechados parece muy probable, por el contexto, que fueran de 180901810.

36 ARJBM. $V, 1,5,32 ; V, 1,5,34$ y $V, 1,5,36$.

37 Huerta JaRAMilLo, A.M., "Pablo de la Llave, un ilustrado entre dos siglos y dos mundos", Llull, vol. 22, n. 44 (1999), pp. 421-430. GIL NovAl.ES, A., Diccionario biográfico del Trienio Liberal. Madrid (1991), p. 356. DE LA LLAVE tuvo algunas responsabilidades en el Gabinete de Historia Natural por encargo de la Junta General, mientras Mociño recibía el mismo encargo del gobierno bonapartista. Se conserva un borrador, fechado en 1811, en el que Mociño, pide benevolencia para su compañero Pablo de la Llave, "por haber abandonado su puesto en Madrid, para ir a América y poder resolver así su lamentable situación económica". Sin embargo permaneció en España, estuvo en Cádiz durante las Cortes. Posteriormente fue canónigo en la Colegiata de Osuna y, más tarde, diputado a Cortes en Madrid durante el Trienio y en México tras la independencia.

${ }^{38}$ ARAM Ms. 1481. leg. $1 \mathrm{C}$ doc. 8. 


\begin{abstract}
Las adjuntas esquelas corroboran mis exposiciones, me disculpan y son un verdadero testimonio.

B.I.m. de Vm. su constante servidor: José Pavón."
\end{abstract}

En 1810, los franceses dejan Madrid y Mociño es detenido. La recuperación del poder por José ${ }^{39}$ permite su regreso, como Director interino, a las dependencias de la Expedición y del Gabinete de Historia Natural, reintegrándose a la Academia de Medicina y figurando como miembro de la Junta Suprema de Sanidad. Pero al retirarse definitivamente los franceses, sale camino del exilio ${ }^{40,41}$. La narración de Pablo de la Llave, publicada por Ricardo Ramírez en la "Reseña de la Expedición de Historia Natural" de la edición de 1891 de la Flora Mexicana, nos da cuenta de las lamentables condiciones en que hubo de salir Mociño:

“...se retiran otra vez los franceses, y en esta retirada, hecha con el mayor desorden y precipitación, y cuando los afrancesados ricos tenían que marchar a pie, ya pueden figurarse la parte de quebranto y apuro que tocaría a Mociño. Llevaba en un carro los efectos más preciosos del Gabinete, sus manuscritos y dibujos, para salvarlo todo. De noche dormía sobre ese carro, seguido a pie de día, hasta que se apoderó de todo un general francés, salvándose sólo los manuscritos y algunos dibujos. No pudo ya volver a España; pasó bastante tiempo en Montpellier, casi ciego y comiendo mendrugos, hasta que algunos sabios franceses y alemanes le socorrieron.”

\title{
d) El exilio y el regreso de Mociño
}

Mociño se dirigió a Montpellier, donde algún auxilio del estado francés y de De Candolle, atenuaron las difíciles condiciones. La aplicación del decreto de Fernando VII de 30 de mayo de 1814, que condenaba a expatriación perpetua a quienes habían recibido cargos públicos bajo el gobierno bonapartista, provocó el ${ }^{42}$

\footnotetext{
39 Mercader Riba, J., José Bonaparte, Rey de España, 1808-1813, Madrid, 1983.

40 Bertomeu SÁNCHEZ, J.R., "La colaboración de los cultivadores de la ciencia española con el gobierno de José |". Ciencias e independencia politica. Comunicaciones del Coloquio Internacional: Las guerras de Independencia, en España y América, en su relación con el pensamiento cientifico (coordinada por Gil Novales, A.), Madrid (1996), pp. 196-203. Ha llamado la atención que Cristiano Hegen, director de la sección de mineralogia, con quien Mociño debió compartir el magisterio en las clases del Gabinete, no sufriese represalias pese a haber jurado también fidelidad a José I.

${ }^{41}$ Soto, D.; Pug-Samper, M.A.; Gonzalez Ripoll, M.D., Científicos criollos e llustración, Aranjuez, 1999.

42 ARAM. Acta del 16 de agosto de 1813.
} 
"reintegro de los papeles, muebles y efectos que pertenecian a la Real Academia de Medicina y que tenía en su poder el Sr. Mociño. Preso entonces por el Gobierno español y hoy fugado con los franceses".

Pasarian tres años más hasta que Pablo de la Llave propusiera, en sesión ordinaria, sin que al parecer encontrara mucho eco, que la Academia de Medicina realizara alguna gestión en favor de Mociño ${ }^{43}$ :

«El vicesecretario hizo presente los buenos oficios que D. J.M. Mociño tuvo con él y el abate Ximenez cuando fueron conducidos a Bayona. Interesando la mediación de este cuerpo para que... facilite su regreso, constándole que aunque fue a Francia no tenía culpa aiguna por ser comprendido en el Decreto de 30 de marzo y sólo lo hizo para evitar ser conducido por segunda vez en la cuerda de galeotes con no poca ignominia por la efervescencia popular en esa aterición y que ofrece las pruebas de lo que lleva expuesto, suplica encarecidamente a esta corporación de sabios ilustrados y filántropos se digne tomar en consideración para elevar a SM los méritos relevantes de D. José Mociño esforzándose en procurar la inquisición de un sabio malogrado con el que se malogra también todo el fruto que debia prometerse a la Nación de la Expedición Botánica a México. No puede menos de empeñar la sensibilidad de sus consocios como el mayor galardón que puede proporcionarse al solicitante. La Academia acordó lo tomaria en consideración..."

El regreso de Mociño a Barcelona, tras el largo y penoso exilio, se produjo entre el 17 de julio de 1817 (ver la última de las cartas a De Candolle) y el 12 de enero de 1818 fecha en que Leandro Fernández Moratín escribia al comerciante barcelonés Juan Grassot: "Ahí tienen Vmds. Al Sor. Mociño...", expresando a continuación sus temores por la suerte de los papeles y dibujos de la expedición ${ }^{44}$.

Mociño murió en mayo de $1820^{45}$, a los 63 años, en casa de Jacobo Villaurrutia a quien, como vimos, había conocido en Guatemala. Fue atendido en su última enfermedad por el Dr. Rafael Esteva. Está documentada la relación de Mociño con la Sociedad Patriótica Barcelonesa en el Acta de la Junta Ordinaria de la Academia de Medicina en la que se dio a conocer su muerte ${ }^{46}$.

"La Academia oyó con enternecimiento la relación que hizo el Sr. Pavón de los trabajos sufridos por el benemérito consocio Sr. D. José Mariano Mociño,

43 ARAM. Acta del 27 de abril de 1816

44 Audioc, R., Epistolario de Leandro Fernández Moratin, Madrid, 1973, p. 712. (Creemos por el contexto de la carta que no es otro que éste el Mociño a quien se refiere.)

45 Lozoya, X., Plantas y luces..., p. 207 (reproduce un acta de defunción de Mociño, redactada en catalán, en estos términos y esa fecha).

46 ARAM. Acta de la sesión de 3 de junio de 1820. 
Secretario de Gobierno y Vicesecretario que fue de esta Corporación, originados de las vicisitudes políticas y que al fin originaron su muerte en mayo de este año ${ }^{47}$ en la ciudad de Barcelona donde por último se habia refugiado. Si la Academia no puede por menos de sentir la pérdida de uno de sus más distinguidos y laboriosos individuos, los elogios tributados a su memoria en los papeles periódicos la han servido de una especie de satisfacción viendo recompensado su mérito y talento por las demostraciones de las personas que saben apreciarlos. Así es que la Sociedad Patriótica de Barcelona asistió en cuerpo al funeral de su sabio Presidente que lo era el difunto Sr. Mociño, y en él perdió la Patria según la expresión de la misma Sociedad un hijo que la honraba por sus modestas virtudes y conocimientos profundos.

La Academia por su presidente y con arreglo al art. 39 acordó se le hiciese el elogio fúnebre y comisionó al efecto al Sr. La Llave, paisano y amigo del difunto, fdo. Vicente Carrasco."

Sin embargo no se han encontrado otros testimonios de la relación de Mociño con la Sociedad Patriótica debido a la escasa información conservada $^{48}$.

\section{e) Los fondos de la expedición}

Los resultados de la REBNE no se publicaron hasta cien años después, cuando el gobierno mexicano impulsado por un grupo de botánicos de aquel país, dio a la imprenta las dos obras principales Flora Mexicana y Plantae Novae Hispaniae ${ }^{49}$ que Sessé y Mociño habían preparado en manuscrito. Se hicieron ediciones entre 1887 y 1894 sólo con texto ante las dificultades para añadir láminas ${ }^{50}$. La primera edición apareció, como apéndice de la revista La Naturaleza, que publicaba la Sociedad Mexicana de Historia Natural; entre 1887 y 1891 Plantae Novae Hispaniae, y entre 1891 y 1897 Flora Mexicana. La segunda edición de ambas la realizó la Secretaria de Fomento del gobierno mexicano en 1893 y 1894.

47 Gil Novales, A., Diccionario biográfico..., p. 439; «... el funeral se celebró el 20 de mayo de 1820 ".

48 Gil. Novales, A., Diccionario biográfico..., p. 439.

GIL Novales, A., Las sociedades patrióticas (1820-23), Madrid, 1975, vol. II, p. 885, y vol. I, p. 8. La prosopografía del vol. II, contiene una breve nota biográfica sobre Mociño en la que se alude también a su papel de Presidente de la Sociedad.

49 Altamirano, F., "Informe que tiene la honra de rendir al Sr. Secretario de Fomento el Director del Instituto Médico Nacional". Anales del Inst. Med. Nal. México. “1897”. (Diciembre 1898 o principios de 1899), pp. 286-293.

50 ARJBM. I, 90,7,1. Carta de Ramón Corona a Miguel Colmeiro y respuesta de éste. México 12-8-1885 y 1-10-1885. (Hay también mención de estos extremos en el Préfacio de la Flora Mexicana. México, 1894.) 
Plantae Novae Hispaniae es en realidad una Flora, semejante a otras que se realizaron abundantemente en el siglo XVIII. El manuscrito en el que se basa recoge los resultados de las exploraciones en la zona central de México, fue preparado en el curso de la expedición y fue sometido a la aprobación de la Corona de 1791 como informe de los trabajos de las tres primeras campañas.

Flora Mexicana es un trabajo menos minucioso, que contiene registros posteriores a 1791. Pese a su nombre, incluye datos y especies de América Central, Cuba, Puerto Rico e incluso California y otras zonas de la Costa del Pacífico hasta del sur de Alaska, no siempre con indicación de la procedencia. Muchos fragmentos de la Flora repiten contenidos de Plantae Novae Hispaniae.

Muy relacionada con las dos anteriores, Flora de Guatemala es obra de Mociño en exclusiva. Es semejante a las anteriores, con las que se complementa, ya que de muchas plantas, salvo las endémicas del Reino de Guatemala, sólo presenta una diagnosis remitiendo a aquellas para las descripciones de detalle.

Aunque los expedicionarios no los publicaron en vida, los materiales de la REBNE fueron utilizados por otros botánicos, por lo que son muchas las plantas mexicanas que no tienen como referencia de autor a Sessé y Mociño aun habiendo sido ellos los primeros en describirlas. Todavía en vida de sus autores, algunas las plantas recolectadas por la REBNE fueron dadas a conocer a la comunidad científica en la publicación de Cavanilles, iniciada en 1791, de los seis volúmenes de los /cones et descriptiones plantarum, obra en la que había más de 600 especies nuevas para la botánica. La obra comprendida 200 especies mexicanas, de las que 185 eran novedades y de ellas 135 procedian de las semillas enviadas por la REBNE, cultivadas en el Jardín Botánico de Madrid (sus descripciones se recogen en los dos primeros volúmenes de la obra y en parte del tercero). Cavanilles no menciona a los botánicos de la Expedición a Nueva España, quienes, sin embargo, sí se interesaron por la publicación según consta en carta de Sessé al ministro Caballero solicitando ejemplares que estaban disponibles en la imprenta real ${ }^{51}$. Desde la muerte de Martín de Sessé, Moció fue el último superviviente de la REBNE, por lo que resultó depositario y responsable de la documentación y materiales. A España llegaron envíos de la Expedición mientras se realizaban las excursiones, tanto especímenes de plantas vivas, plantas desecadas en herbario y muestras

51 AMNCN. leg. 2. carp. 5. Solicitud de Sessé a J.A. Caballero de 26-4-1806. 
zoológicas como descripciones, listados de materiales y dibujos. Los ejemplares enviados a Madrid se destinaban al Jardín Botánico y al Gabinete de Historia Natural para su exhibición, almacenaje y conservación, así como, en el caso de plantas vivas y semillas, para procurar su aclimatación y cultivo, previendo, en los casos aconsejables, que esa aclimatación se realizara en los jardines botánicos idóneos, como el del Puerto de Santa María o el de Tenerife.

Miguel Colmeiro, que fue director del Real Jardín Botánico de Madrid a mediados del siglo pasado, ha dejado una interesante obra para conocer lo que se sabía de los fondos de la REBNE en aquel momento. La primera parte, que titula Biblioteca Botánica Hispano Lusitana, es de gran importancia para saber cuáles eran los importantes documentos, manuscritos y láminas que acompañaron a Mociño durante su exilio. La sección quinta nos da noticia de los documentos que conocía este autor acerca de la expedición y de sus protagonistas. En la segunda parte, dedicada a los estudios biográficos, señala que el Jardín Botánico de Madrid ${ }^{52}$

"poseía ya antes de 1815 , el herbario y parte de los manuscritos que se completaron el año 1820 , después de varias vicisitudes, pero no así la colección de dibujos... el número de plantas dibujadas se acercaba a mil cuatrocientas, y habia además otros tantos dibujos de animales, siendo muy considerable el número de especies nuevas...”

La suerte de gran cantidad de materiales de la REBNE fue muy accidentada. Los revisaremos en tres apartados: dibujos, especimenes (plantas secas en herbario) y escritos (especialmente los manuscritos científicos elaborados durante el estudio de las plantas recolectadas).

\section{LOS DIBUJOS}

Las expediciones científicas ilustradas, con el fin de dar un reflejo preciso de las observaciones añadian a las descripciones literarias los objetos vivos o disecados, en los casos en que era posible, e imágenes realizadas, con un criterio que podriamos llamar hoy fotográfico, cumpliendo indicaciones muy precisas ${ }^{53}$. En efecto, como decía Gómez Ortega en sus instrucciones a los ilustradores:

52 Colmeiro, M., La Botánica y los botánicos de la Península Hispano-Lusitana. Madrid, 1858, p. 185 .

${ }_{53}$ Zabala Mouriz, A., y Sanchez Gómez, B., “La imagen gráfica de la REBNE», en La Real Expedición Botánica..., pp. 273-294. 
“... copiar exactamente la naturaleza, sin presumir corregirla ni adorarla. como suelen hacer algunos dibujantes que añaden adornos sacados de su imaginación, cuidando la escala y los colores para que reproduzcan fielmente los objetos".

Hasta tal punto las imágenes producidas tienen importancia científica que la identificación de especies, en algunos casos, ha sido resuelta basándose en los dibujos que incluian, si era posible, el despiece floral, un fruto y una porción con hojas y ramas o alguna parte significativa para la discriminación. Se procuraba hacer los dibujos antes que al secarse se alterasen el color, la textura y demás condiciones de la planta, y dado que estaban destinados a servir de base a grabados, era frecuente dejar algunas partes delineadas que, si había tiempo, se completaban posteriormente. De los dibujos se realizaban duplicados para los Jardines Botánicos madrileño y mexicano.

Las láminas de la REBNE son de enorme importancia artistica y científica a pesar de haber contado con unos recursos comparativamente pequeños para su realización, ya que tuvo adscritos solamente dos pintores que fueron peor retribuidos que los de otras expediciones - la de Mutis, contó hasta con 18 pintores trabajando simultáneamente, con un sueldo de 1.000 pesos, mientras que los de Nueva España cobraban solamente 500 - a pesar de lo cual la calidad de la obra de los artistas de la REBNE fue reiteradamente alabada:

“de Mariano(sic.) Echeverría aseguró Lagasca en 1815 ser el mejor dibujante naturalista que habia en Europa" ${ }^{54}$.

Sessé intentó, a lo largo de todo el desarrollo de la Expedición, que sus dibujantes fueran mejor considerados por la administración, como evidencia esta carta dirigida al virrey Revillagigedo ${ }^{55}$.

"Desde el principio de la Expedición tuve cuidado de examinar los trabajos de sus dibujantes, que seguramente exceden en propiedad y delicadeza a cuantos yo he visto de su clase, y si cuando informé de acuerdo con el director del Jardín, sobre el sueldo que debía señalárseles, hubiera previsto su buena conducta y sobresaliente habilidad, que empezaron a manifestar desde el segundo año, hubiera dicho que se les señalase el mismo sueldo que a los dibujantes de las demás Expediciones, esto es el de un mil pesos, e igual gratificación en sus viajes, no habiendo razón para que siendo igua-

54 Jaramillo Arango, J., Hipólito Ruiz. Relación histórica del viaje a los reinos de Perú y Chile, Madrid, Real Academia de Ciencias Exactas, Físicas y Naturales, 1952, p. 511.

55 ARAM. Serie documental 66. Carta de Sessé a Revillagigedo, 11-1-1794. 
les, sino superiores en mérito, se les rebaje la recompensa con general sentimiento de sus patricios y en algún modo, desaire de esta Academia la cual se debe fomentar con el premio debido a sus alumnos beneméritos como lo son D. Atanasio Echeverría y D. Vicente de la Cerda.

En esta consideración, y la de que dichos artistas, se contentan con menos gratificación de la que merecen, y disfrutan los empleados en iguales destinos; me parece que justo que se les conceda. Sobre todo V.E. podrá resolver lo que fuera de su superior agrado D.G. a V.E. muchos años. México 11 de enero de 1794."

También se ocupó Sessé, durante el verano de 1792, por otro aspecto de la obra gráfica de su Expedición, intentando adelantar los trabajos de grabado. En una carta al virrey Revillagigedo de 23 de mayo le advertia:

"Con motivo de haberse emprendido en España diferentes y grandes obras de grabado apenas se halla artista de mérito en esta clase que no se halle ocupado por muchos años en las que por subscripción se hacen de todas las pinturas antiguas del Real Palacio y de los más famosos héroes de la Nación y aunque se ha considerado preciso enviar muchos dibujos a las costas extranjeras para con la ayuda de grabadores puedan los accionistas poseer cuanto antes estas colecciones apreciables.

De aqui se infiere la mucha tardanza y trabajos que se ha de haber para la publicación de las obras en que se ocupan las cuatro expediciones botánicas en diferentes dominios de las Américas, sin contar los destinados a dar la vuelta al mundo, siendo muy de temer que la de este Reino experimente el mayor atraso respecto a ser la última que ha emprendido su obra y la que debe retirarse después de todas.

Hace cuatro años que lo verificaron los botánicos del Perú y hasta ahora se ignora que se haya empezado la edición de su Flora sin poder atribuir esta demora a otra causa que la falta de grabadores peritos.

Estos recelos y la consideración de que en esta Academia hay ya algunos pensionistas adelantados que dirigidos por el maestro D. (...) Fabregat, podrán trabajar con perfección, utilidad y economía del Real Erario me hacen exponer a V.E. que podrian dedicarse al ramo de la Historia Natural D. Tomás Zuria, Julián Marchena y José Mariano del Águila a quienes se gratificaría con proporción al mérito de sus trabajos para que, con aprobación de S.M. a quien se remitirian las primeras muestras sigan ocupadas únicamente en este objeto tan importante D.G. a V.E. 23 de mayo de 1792.»

La respuesta no debió ser del todo desfavorable, porque en una nueva carta al virrey Sessé se mostraba satisfecho de que los mencionados dibujantes dedicaran la mitad de su tiempo a auxiliar a la REBNE y pedía a Revillagigedo que, en su momento, se encargara de supervisar las obras 
realizadas para recompensarlas adecuadamente. La contestación del virrey, favorable a esta propuesta, tiene fecha del 13 de junio de $1792{ }^{56}$.

Se realizaron también dibujos de animales y de la excursión a Nutka se conservan varios de valor antropológico y algunas láminas con vistas de la entrada del fondeadero que, aunque en su mayoría se atribuyen a dibujantes de otras expediciones, en algunos casos deben ser obra de Echeverría, ya que así figuran mencionados en una carta de Sessé al virrey Branciforte:

"...se han concluido con el mayor esmero los dibujos de Nootka que V.M. espera ${ }^{57}$ ".

De los dibujos de la Expedición a Nueva España existe una colección en el Conservatorio del Jardín Botánico de Ginebra, conocida como Flora de las Damas ${ }^{58}$.

En el Jardín Botánico de Madrid existe una pequeña colección, que San Pío Aladrén, conservadora del Archivo del Jardín Botánico de Madrid, describe de la siguiente manera:

“119 dibujos de gran belleza, a la acuarela... el catálogo de estos dibujos se publicó en el libro editado con motivo de la exposición sobre la Expedición Botánica a Nueva España que se celebró en el Pabellón Villanueva del RJBM en 1987. El estado de conservación es bueno, cinco de ellos fueron sometidos a restauración y se han reproducido en diapositivas de $35 \mathrm{~mm}$. y existe asimismo una colección de transparencias fotográficas de $9 \times 12 \mathrm{~cm}$. que son aptas para su reproducción en libros o trabajos ${ }^{57}$ ".

McVaugh ${ }^{60}$ ha comprobado que las láminas de Madrid fueron enviadas a España, junto al manuscrito original de Plantae Novae Hispaniae, desde México en 1791. Las láminas están listadas y numeradas por Mociño aunque su numeración no concuerda con los números de Icono, Ic. Fl. Mex., que acompañan a la descripción de algunas especies del manuscrito, salvo en uno de los casos, IC. Fl. Mex. 428, que corresponde a Begonia

\footnotetext{
56 ARAM. Serie documental 66. Cartas de Sessé a Revillagigedo 23-5-1792 y $6-1792$ y respuesta 13-6-1792.

57 ARAM. Carta de Sessé al virrey Branciforte 13-3-1797.

58 Ver el comentario de la $2^{a}$ carta de Mociño a De Candolle.

59 San Pio AladRén, P., "Fondos documentales manuscritos e iconográficos de la REBNE en el archivo del RJBM". Homenaje a Martín de Sessé y Juan del Castillo, Huesca, 1993. (La obra incluye la reproducción de $\mathbf{2 0}$ de las láminas conservadas en el RJBM.)

60 McVaugh, R., «Botanical results of the Sessé and Mociño Expedition (1787-1803): VI Reports and records from western Mexico, 1790-1792". Boletín del Instituto de Botánica, Época 3 , vol. 6, número 1 -monográfico-, Univ. Guadalajara, México, 1998, p. 18.
} 
balmisiana, de la que, por otra parte, no parece haber otra copia ni en Ginebra ni en la Fundación Hunt.

En el Herbario Nacional de México se encuentra actualmente una copia de la colección del Jardín madrileño realizada por el botánico mexicano Fernando Altamirano durante su visita a Madrid en 1898 con vistas a la publicación de la Flora Mexicana. Sin embargo, como vimos, la publicación no incluyó finalmente ilustraciones.

La colección más importante de los aproximadamente 2.000 dibujos y acuarelas realizados por la REBNE la constituyen las láminas originales de la Expedición que acompañaron a Mociño en el exilio y que, a su regreso, permanecieron cerca de 150 años en paradero desconocido. Durante mucho tiempo lo último que se supo de ellas es que en 1844-45 estaban en poder de Felipe Esteva, pariente del médico que atendió a Mociño en sus últimos días, y desde esa fecha se daban prácticamente por perdidas. Actualmente la colección es propiedad del Hunt Institute of Botanical Documentation de la Carnegie-Mellon University de Pittsburgh, Pennsylvania, Estados Unidos, desde que la Fundación Hunt las compró a los hermanos Luis y Jaime Torner, pertenecientes a una familia barcelonesa, en cuyo poder estaban ya, al parecer, en 1880. La colección, formada por 18 volúmenes encuadernados de aproximadamente 100 páginas cada uno, fue mostrada a un restaurador barcelonés apellidado Gudiol que sugirió en 1979 a los hermanos Torner que se pusieran en contacto con la Universidad de Pittsburgh. La Universidad americana, a través del director de la Fundación Hunt, Robert W. Kieger, del subdirector, T.D. Jacobsen, y del abogado D. Beuger, se mostró interesada en adquirirlas y entabló negociaciones que llevaron al acuerdo de compra por un total de cuatro millones de pesetas, es decir unas 2.000 pesetas por lámina, en enero de 1981. La colección es conocida desde entonces como "The Torner Collection of the Sessé and Mociño Biological Illustrations", siendo nombrados los antiguos propietarios Conservadores Honorarios del Instituto Hunt. Las gestiones de las autoridades que representaban a la administración española no consiguieron detener o deshacer la operación para retener la colección dentro del patrimonio español. En un artículo del diario El País de 12 de junio de 1986 se recogen algunas circunstancias de la transacción ${ }^{61}$. La colección iconográfica depositada en EE.UU. se ha dado a conocer recientemente ${ }^{62}$.

\footnotetext{
61 Garcia A., “2.000 láminas del siglo XVIII salieron de España en 1981 con permiso de la Junta de Exportación". Articulo del diario El País. Madrid 12-6-1986.

62 The Torner Collection of Sessé \& Mociño. Biological Illustration, Hunt Institute of Botanical Documentation, CD-Rom, Pittsburg, 1998.
} 


\section{LOS MANUSCRITOS}

Los manuscritos más importantes desde el punto de vista botánico se encuentran en el Real Jardín Botánico de Madrid, en la llamada actualmente división $\mathrm{V}$ del Archivo, reunidos en siete legajos, destacando, sobre todo, los valiosos manuscritos de las dos obras Plantae Novae Hispaniae y Flora Mexicana, que ya sirvieron para las ediciones mexicanas de hace un siglo. También se incluyen en este apartado los manuscritos originales de Mociño: Flora de Guatemala y Plantas descritas por D. Juan del Castillo en el viaje a Acapulco.

En el manuscrito Plantae Novae Hispaniae, formado por dos tomos en folio con más de 550 páginas cada uno, muy elaborado por sus autores, escrito en latín y con las plantas ordenadas según la clasificación de Linneo, se describen 1400 especies de las que 700 son primicia. El manuscrito de la Flora Mexicana, formado por tres volúmenes, redactado con un estilo menos convencional, contiene 1500 especies de las que, al menos, 450 estaban ya en Plantae Novae Hispaniae, y también 150 especies nuevas.

El Archivo del Museo de Ciencias Naturales conserva y tiene microfilmados importantes documentos generados por la REBNE, cuya excelente catalogación facilita su localización y consulta ${ }^{63}$. Además, recientemente se ha identificado entre otros manuscritos depositados en la biblioteca del Museo, la obra ornitológica de la REBNE ${ }^{64}$. La Real Academia de Medicina de Madrid tiene, finalmente, una importante colección documental relacionada con la REBNE ${ }^{65}$.

\section{EL HERBARIO}

El Jardín Botánico de Madrid posee, además de la documentación gráfica y escrita, un tipo de documento específico de enorme valor tanto desde el punto de vista botánico como histórico, el herbario MA ${ }^{66}$, que forma parte del Patrimonio Histórico Español. Contiene aproximadamente

63 Calatayud Arinero, M.A., Catálogo de las expediciones y viajes científicos españoles. Siglos XVIII $y$ xix, Madrid (1984). "Los fondos documentales de la REBNE en el MNCN", en La Real Expedición..., pp. 243-251.

64 Puig-Samper, M.A., y Zamudio, G., "Un manuscrito inédito de la Real Expedición Botánica a Nueva España (1787-1803) sobre ornitología mexicana". Asclepio, vol. L-1 (1998), pp. $251-254$.

65 Maldonado, J.L., y PinaR, S., Catálogo de los fondos manuscritos del S. xvill de la RANM, Madrid (1996).

66 Blanco Fernandez-Caleya, P., «identificación de los tipos en los herbarios históricos», en Ciencia, vida y espacio en Iberoamérica, Madrid, 1989, vol. 1, pp. 209-223 - MA son las siglas con que se designa internacionalmente el herbario del RJBM-. 
un millón de ejemplares de plantas distribuidas en tres grandes apartados. Aquí interesan las colecciones históricas, dentro de las cuales el herbario de Sessé y Mociño supone una aportación fundamental, junto con los de Mutis, Ruiz y Pavón, además de los de Cavanilles y Lagasca.

El Herbario de Sessé y Mociño permaneció sin que nadie se ocupara de su estudio, desde mediados del siglo pasado hasta su envío en préstamo a los Estados Unidos en 1936 por el entonces director del Jardín Botánico José Cuatrecasas (1903-1996). Fue fotografiado íntegramente y reetiquetado, procediéndose al montaje en los casos en que el original se había alterado o deteriorado, en el Chicago Natural History Museum, donde P.C. Stanley, especialista en flora mesoamericana, se comprometió a organizar e identificar todo el material, y la institución a publicar sus conclusiones. Stanley se jubiló antes cumplir los compromisos quedando durante un tiempo paralizado el proyecto. En 1945 se solicitó la devolución del herbario resultando infructuosas todas las gestiones hasta 1963, en que se consiguió su regreso. En 1979, con las relaciones entre España y Estados Unidos regularizadas, se enviaron, esta vez a la Smithsonian Institution en Washington, algunos pliegos con ejemplares pendientes de identificar, según refería Cuatrecasas ${ }^{67}$. De la coordinación de este trabajo se encargó McVaugh, que desde 1958 ha trabajado en la descripción y valoración total de la contribución botánica realizada por al Expedición.

Muchos géneros y especies vegetales han sido descritos e identificados a partir de piezas que, perteneciendo originalmente a la REBNE, fueron dispersadas por diferentes colecciones privadas y públicas de todo el mundo. Conviene recordar que desde la salida de Mociño al exilio los materiales estuvieron en la oficina de la Expedición de Ruiz y Pavón y está documentado que Pavón vendió ejemplares tanto de su propia expedición como de la REBNE. Grobet ${ }^{68}$ afirma que entre 1819-1824 Pavón vendió al coleccionista inglés A.B. Lambert 15.000 especímenes botánicos y zoológicos. McVaugh sostiene que Pavón entre 1814 y 1828 "pudo sacar varios miles del herbario de Sessé y Mociño, quizás 6.000 especímenes duplicados" ${ }^{69}$. Los especímenes enviados por Pavón llevaban frecuentemente una etiqueta escrita a mano con las siglas N.E. (Nueva España), sin el nombre del recolector ni otros datos salvo el nombre linneano, comúnmente el otorgado por Sessé y Mociño. Las razones de Pavón para reali-

67 Blanco fernandez-Caleya, P., «identificación de los tipos...», p. 221.

68 Grobet Palacio, R., El peregrinar de las flores mexicanas, Méjico, 1982.

69 McVaugh, R., "Botanical results of the Sessé and Mociño expedition», Taxon (1987), pp. 168-170. 
zar este tráfico apuntan a una combinación de necesidades materiales y búsqueda de la estima en el mundo científico europeo del momento.

Algunas plantas que hoy se encuentran en los herbarios de los Jardines de Kew, Herbario K, en Gran Bretaña, formando parte de las colecciones de Pavón, pertenecen a la flora mexicana y no se encuentran en Perú ni en Chile, lo que indica que Pavón vendió, junto a ejemplares de herbario de su propia expedición, los de Nueva España. Por otra parte, una pequeña colección de plantas mexicanas existentes en el herbario de Kew pudiera haber sido proporcionada por el propio Mociño ${ }^{70}$. En Gran Bretaña existen además especímenes con referencia a Sessé y Mociño en Herbario BM (British Museum of Natural History) y en Herbario OXF (Fielding-Druce Herbarium, University Oxford).

A la muerte de Lambert su herbario, y con él una parte de las plantas de Nueva España, fue a parar a Ginebra, Herbario G y Herbario G-DC. Por su parte, otro coleccionista, P.B. Webb, adquirió ejemplares (algunos directamente de Pavón en 1826-27, otros a través de Lambert), que fueron legados al Duque de Toscana, y, como resultado, hoy se encuentran en el Instituto Botánico de Florencia 2.345 ejemplares de herbario de Nueva España, Herbario FI (Herbarium Universitatis Florentinae, Florencia). Finalmente, hay una cantidad no precisada de ejemplares de la REBNE en Herbario F (Field Museum, Chicago) y en colecciones privadas.

\section{LAS CARTAS}

Las cuatro cartas que dirige José Mariano Mociño a Agustín Pyramus De Candolle son la parte más novedosa de este estudio. Se encuentran en el Conservatorio del Jardín Botánico de Ginebra y forman parte del legado Correspondencia botánica de Agustín Pyramus de Candolle 1778-1841. Donación de la Sra. de Agustín de Candolle y sus hijos a los archivos del Conservatorio de Ginebra 1924. Es decir se conservan merced a una donación de la familia De Candolle. Su localización y acceso han sido posibles gracias a la inestimable colaboración de Mr. H. Bourdet.

\section{$1^{a}$ carta: Transcripción}

A Monsieur Mr. Decandolle Directeur du jardin de plantes, et professeur de botanique à l'ecole de medicine de Montpellier.

70 Blanco Fernandez-Caleya, P., "Los herbarios de Sessé y Mociño", en La Real Expedición..., Madrid, 1987, pp. 256-257. 
à Paris.

Monsieur, et mon cher ami,

II a plusieurs jours que je suis malade et quoique la maladie n'est pas dangereuse de sa nature, elle me fait souffrir toujours.

Bien assuré que vous avez et la volontè, et la bontè de vous charger de mes manuscrits, je dois vous prevenir, que en cas que Madame Zea ait changè de logement, vous pouvez prendre des reseignements sur sa nouvelle habitation chez Mr. le Duc de Santa $\mathrm{Fe}$, à qui je vous prie de faire une visite à mon aussi que á la Duchesse son epouse. Il est bien connu à París, et vous trouverez un personage bien aimable.

Je vous acompagne dans votre chagrin pour la perte de votre grand beau pere.

...........

je vous prie de vous faire mes compliments a Madame votre epouse et de compter toujour avec l'inutil estime de

Votre tres reconnoissant ami et serviteur.

Firma J. Mocigno

le 18 septembre 1815 .

\section{Traducción}

Fechada el 18 de septiembre de 1815.

A Mr. Decandolle Director del Jardín de Plantas y profesor de botánica de la escuela de medicina de Montpellier, en Paris.

Señor y querido amigo:

Hace varios días que estoy enfermo y aunque la enfermedad no es peligrosa por su naturaleza me hace sufrir constantemente.

Completamente seguro de que tenéis la voluntad y la bondad de encargaros de mis manuscritos debo preveniros que, en caso de que la señora Zea haya cambiado de alojamiento podéis tomar las señas de su nueva dirección en casa del Sr. duque de Santa $\mathrm{Fe}$ a quien os ruego hagáis una visita en mi nombre así como a la duquesa su esposa. Él es muy conocido en París y os resultará un personaje muy amable.

Os acompaño en vuestro pesar por la pérdida de vuestro abuelo.

Os piso presentéis mis cumplidos a vuestra señora esposa y que contéis siempre con la inútil estima de

Vuestro muy agradecido amigo

Mocigno (sic.)

18 de septiembre de 1815 .

\section{Comentario.}

Agustín Pyramus De Candolle, que habia nacido en Ginebra en 1778, ocupaba en esas fechas la cátedra de botánica aneja a la dirección del 
Jardín Botánico de Montpellier. Tenía gran prestigio como botánico, comparable al de Cuvier o Lamarck quien le encargó la redacción de la tercera edición de la Flora Francesa ${ }^{71}$. Fue autor del Prodromus Systematicus Naturales Regni Vegetabilis, que comenzó a publicar en 1824 y alcanzó 17 volúmenes, los siete últimos a cargo de sus descendientes, entre los que destacó especialmente su hijo Alphonse.

En medio de las penalidades que sufrió Mociño durante su exilio, el encuentro con Agustín De Candolle tuvo gran importancia. La relación de ambos está recogida por Miguel Colmeiro en su obra La Botánica y los Botánicos de la Península lbérica ${ }^{72}$.

“...Desde 1808 De Candolle era profesor de Botánica y director del Jardín Botánico de Montpellier al ver las manuscritos y dibujos de Mociño formó de su importancia la más alta idea. Esto y las pocas esperanzas de volver a su patria, que Mociño tenía, y más aun el creer poco duradera su vida, le inclinaron a encomendar el depósito de tanta riqueza científica al célebre $\mathrm{De}$ Candolle.»

La señora Zea, a través de quien mantuvieron contacto Mociño y De Candolle, es la esposa de Francisco Antonio Zea, que se significó tanto en los ambientes científicos como en los políticos. Fue uno de los diputados de Bayona y acompañó a José I durante su retirada a Burgos ${ }^{73}$. Colmeiro en su obra se refiere a él en los siguientes términos:

“Español-americano, natural de la provincia de Antioquía, que fue discipulo de Mutis y estuvo encargado de contribuir, en los años 1791 o 1792, a las exploraciones botánicas comenzadas por su maestro en Nueva Granada. Necesitó venir a España en el año 1797 por haberse creido que conspiraba en aquel país; pero la mediación de Mutis bastó para facilitarle una buena acogida en Madrid, y se le permitió ir a París para consultar a varios botánicos sobre algunas plantas de la Flora de Nueva Granada.»

Probablemente Zea conoció a De Candolle en aquella época. Posteriormente volvió a Madrid y, a la muerte de Cavanilles en 1804, fue director del Jardín Botánico de Madrid, cargo al que, como se vio, aspiró también Sessé. En 1809 dejó la dirección del Botánico, que de hecho estaba siendo desempeñada por su discípulo Lagasca. Al producirse la retirada de José I hacia Burgos Zea formó parte del séquito, desde Francia

\footnotetext{
De Candolle, A.P., Regni vegetabilis systema naturae, 2 vols. Paris, 1817.

Colmero, M., La Botánica y los botánicos, p. 185.

Artola, M., Los afrancesados, Madrid (1989), p. 111.
} 
pasó más tarde a Gran Bretaña. Colaboró posteriormente con Bolivar en la independencia de las repúblicas sudamericanas y, en 1820, desempeñó alguna misión diplomática cerca del embajador español en Londres $^{74}$.

Miguel José de Azanza, duque de Santa Fe, fue referencia para muchos exiliados en aquellos años, entre otras razones porque colaboró con la comisión creada para establecer la relación de los exiliados es. pañoles a los que el gobierno francés había determinado ofrecer algún socorro ${ }^{75}$.

Ministro de Guerra con Carlos IV en 1793 y virrey de Nueva España entre 1798 y 1800 , precisamente en sus años en México, tuvo relación con Mociño y, como vimos, autorizó la demora del regreso de la expedición de Guatemala. De vuelta en España se opuso a Godoy, por lo que gozó de la confianza de Fernando VII, que en 1808 le nombró Ministro de Hacienda. Posteriormente participó en la Junta de Gobierno durante la estancia de Fernando VII en Bayona, adonde se trasladó él mismo para presidir la Junta de Notables que redactó la Constitución de Bayona de 1808. Reconoció a José I, quien le nombró Ministro de Justicia y posteriormente de Asuntos Exteriores y, en 1810, embajador extraordinario en París. Fue entonces cuando se le concedió el título de duque de Santa Fe y caballero del Toisón de Oro. Presidió el Consejo de Ministros durante el viaje de José I a Paris en $1811^{76}$. Ejemplo arquetípico de afrancesado, fue duramente atacado por esa condición. Durante su exilio escribió, con O'Farril, la célebre Memoria sobre los hechos que justifican su conducta política desde marzo de 1808 hasta abril de 1814. Murió en Burdeos en 1826. La indicación de Mociño a De Candolle para que lo visite indica la buena relación que mantenía con el duque.

Las quejas de Mociño sobre su mala salud parecen corresponderse con el lamentable estado con que era descrito por su discípulo Pablo de la Llave en sus últimos tiempos en España. La carta es una confirmación de primera mano sobre la salida de España de los documentos que fueron cedidos a De Candolle. Cesión sobre la que hay otras referencias pero que aquí tenemos en boca del interesado. Mociño confió efectiva-

Soto, D., Francisco Antonio Zea, Aranjuez (1999).

ARtola, M., Los afrancesados, p. 223.

A ARtola, M., Los afrancesados, p. 173, reproduce el Decreto. "Artículo $1^{\circ}$. Los ministros se reunirán, al menos una vez por semana en Consejo, bajo la presidencia del duque de Santa Fe...". Archivo Histórico Nacional, Consejos leg. 49613. 
mente a De Candolle manuscritos y láminas. Cuando al abandonar Montpellier trató de devolvérselos, Mociño rehusó recuperarlos, probablemente convencido de que nunca regresaría a España y no llegaría a verlos publicados.

Mociño en esta carta, no así en otras, afrancesa la ortografía de su apellido, aunque el modo en que aparece escrito en diferentes documentos muestra un gran repertorio de variantes, tanto por los problemas de la eñe, frecuentemente convertida en ene -Mocino-, como por los de la ce, que aparece también frecuentemente como ceta o cedilla, Moziño, Moçiño ${ }^{77}$.

\section{$2^{a}$ carta: Transcripción}

Alais 17 de Avril 1817

A. Mr. Decandolle.

Mon trés cher ami. Je me trouve dans () de quitter la France pour me rendre en Es(pagne). J'y vais sans objet, et seulement reduit (a ce) que l'exercise de la medicine puisse me pr(oduire). Pour l'en verifier j'ai bessoin de porter a(vec moi touts mes desseins, sans ce que je serai in(évita)blement mené de prisson en prisson, jusqu'(a je) ne sais pas. C'est por cela que je vous (prie?) de me remettre le plûtot possible les des(seins) que je vous ai confiè à Montpellier, à (les) adressant à Mr. Dunal (Duval?) ou a Mr. Lich(estein).

Je pense de me rendre a Barcelon(ne, et je) vous prie de même de m'envoyer quelque (lettre) de recomendation pour les naturalistes que () avoir dans cette ville. Vous savez que (je suis) ètranger dans l'ancien continent dan(s le) quel je ne compte que dans le faveur () de quelque ami. Vous savez aussi (l'état).

..../...

de ma santè la quelle ne me promet pas de vivre long temps. Je voudrais passer les restes de mes jours de tout mon mieux; et j'espere que vous contribuirez à ce benefice en me remettan les desseins, et les lettres de recomendation que je vous ai prie de m'envoyer.

Les delais sont très couts, car les petits secours que le gouvernement français me donnaient, m'ont déjà manqué.

Je n'espere pas d'autres que ceux que vous et d'outres amis bienfaiteurs ont voulu m'assigner.

Faites moi le plaisir de rendre mes respetueux compliments à votre chere epouse. Ma tendre amitié à vos enfants. Et vous mon cher, soyez toujours persuadé que je suis votre devoué ami et seviteur.

Firma J. Mociño

77 JaRamillo Arango en la introducción de Relación del viaje al Perú..., t. 1, p. XXXIV, atribuye a Mociño el uso continuo de la $z$ en su apellido, afirmación desmentida por la documentación conservada. 
Traducción.

Fechada en Alais 17 de abril de $1817^{78}$.

A Mr. Decandolle.

Mi muy querido amigo. Me encuentro en trance de marchar de Francia para ir a España. Alli voy sin objeto y solamente reducido a lo que el ejercicio de la medicina pueda producirme. Para su verificación necesito llevar conmigo todos mis dibujos sin los que sería probablemente llevado de prisión en prisión hasta no sé cuando. Por eso os pido me devolváis lo más pronto posible los dibujos que os confié en Montpellier dirigiéndolos a Mr. Dunal o a Mr. Lichtenstein.

Pienso dirigirme a Barcelona y os pido también que me enviéis alguna carta de recomendación para los naturalistas que pueda encontrar en aquella ciudad. Como sabéis soy extranjero en el Antiguo Continente en el que no cuento más que con el favor de algún amigo. Sabéis también el estado de mi salud la cual no me permite vivir mucho tiempo. Quisiera pasar el resto de mis dias del mejor modo y espero que contribuyáis a este beneficio, remitiéndome los dibujos y las cartas de recomendación que os he rogado me enviéis.

Los plazos son muy cortos pues los pequeños socorros que el gobierno francés que daba ya me faltan.

No espero más que aquello que vos y otros amigos benefactores han querido asignarme.

Dadme el placer de rendir mis respetuosos saludos a vuestra querida esposa. Mi tierna amistad a vuestros hijos y vos querido estad siempre seguro que soy vuestro devoto amigo y servidor.

J. Mociño.

Comentario. ${ }^{79}$

Desde Alais, Mociño pide que el envío que solicita se haga a Montpellier, donde debía resultarle más accesible, pues habia trabajado allí

78 Es posible que COLmelro conociera esta carta, aunque no se refiere a ella, ni hay constancia de haber sido publicada, pero en La Botánica y los botánicos..., p.185 precisa que Mociño pidió a De Candolle sus dibujos "en abril de 1817".

79 Por problemas técnicos la reproducción manejada es deficiente, haciéndose preciso suplir la carencias en el margen derecho de la primera página por la lectura en espejo en el dorso, cuando ha sido posible. Se indica entre paréntesis, en la transcripción, la reconstrucción de los fragmentos mutilados en la reprografía. 
con Dunal, un discípulo de De Candolle, quien en sus memorias ${ }^{80}$ recuerda que:

"con ayuda de Félix Dunal y del propio Mociño en 1813 comencé a describir y clasificar las especies que estaban representadas en la colección de pinturas... que toda la colección, incluyendo duplicados, estuvo en mis manos entre 1813 y 1817 ",

advirtiendo que la colección que quedó en su poder después de esa fecha

"consiste en 309 originales duplicados que me fueron regalados por Mociño antes de su posterior salida de Francia".

En 1817 el regreso parece posible, Mociño quiere recuperar los dibujos que son indispensables para ir a España con garantias y además resultan fundamentales en la publicación que se pretende. Entonces ocurrió el episodio, citado en sus memorias por De Candolle, quien refiere cómo, siendo ya Director del Botánico de Ginebra, hubo de devolver a Mociño en corto plazo sus dibujos originales, realizándose una colección de copias, para lo que contó con la generosa colaboración de muchas personas, estudiantes, aficionados a la botánica y damas de la buena sociedad, que en pocos días realizaron las réplicas que se sumaron a algunos dibujos regalados por Mociño ${ }^{81}$. La conocida como Flora de las damas (por haber sido Mme. Lavit la encargada de organizar entre sus amistades los detalles de la copia) está en el Conservatorio del Jardín Botánico de Ginebra. Comprende 13 tomos en folio y tiene el largo título de: Flora de México o colección de plantas raras o poco conocidas observadas en México y en la Nueva España por Sessé Mociño y Cervantes, dibujados en el pais por Echeverría, Cerda, etc., copiados en Ginebra por un grupo de aficionados a la pintura y a la botánica, clasificados y nombrados después los dibujos y las descripciones originales por De Candolle y conocido como Flora de las Damas.

En 1813 De Candolle había publicado la Théoríe élementaire de la Botanique, que constituye un antecedente del actual Código Internacional

CANDOlle de, A.P., Memoires, Ginebra (1862), pp. 219-221.

${ }^{31}$ COLmeiro, M., La Botánica y los botánicos..., p. 186, afirma que «doscientos individuos de uno y otro sexo tomaron parte en este trabajo, logrando concluir en ocho o diez dias más de 860 dibujos, dejando 109 delineados en contorno. En Montpellier habian sido copiados 71 y de los duplicados en la colección original habia cedido Mociño a De Candolle 305 ". 
de Nomenclatura Botánica por las precisiones terminológicas que no siempre habían sido aplicadas por los botánicos de la REBNE. El mismo De Candolle dice haberse dado cuenta de la gran cantidad de especies nuevas representadas, pero también de muchos errores en los nombres (He hecho entender a Mociño la necesidad de revisar todos los nombres). Clasificó y describió las novedades tan cuidadosamente que después de años son pocos los cambios que hubo que hacer cuando encontré las mismas especies en herbario o en la literatura especializada, lo que da idea de la importancia científica de la documentación gráfica que aportaban las láminas.

Los lamentos de Mociño sobre sus problemas económicos confirman la escasez de las ayudas de la administración francesa, y la referencia al ejercicio de la medicina como medio de subsistencia nos recuerda su actuación en la fiebre de Andalucía o en la cabecera de Sessé durante la enfermedad que acabó con su vida, de la que se conserva una descripción cuyo manuscrito contiene incluso una receta extendida de su puño y letra ${ }^{82}$.

\section{$3^{a}$ carta: Transcripción}

\section{Moçino 27 mai 1817}

A Monsieur De Candolle à Montpellier.

Mon très cher ami. J'ai regreté toujours l'impuissance de vous revoir si vous ne restiez comme on m'a êté dit plus longtemps à Montpellier. Mon ami Gomez Hermosilla est chargé de tout ce qui me concern, et il se rendra chez vous faire les remerciements que je dois a vôtre bonté, et pour prendre les soins de mes dessins; car j'ai une certaine fierté de caracter qui ne me permet pas demander quelque faveur à des hommes miserables, qui à present sont (sur mon esprit?).

Je ne demanderais pas la feuille de route pour me transfere, je ne sais pas oû. Mais toujours j'aurais la reconnaissance que je dois à vôtre bienfaisance, et vous ne trouverez jamais.

.......

ingrat un viellard dans l'age, et bien petit dans I'histoire naturelle qui vous aime, et vous aimera toujours vôtre constant et reconnaissant ami et très humble serviteur.

J. Mociño

82 ARAM. MS. 1635. Curiosisima relación de la enfermedad padecida por Martín de Sessé y del tratamiento a que estuvo sometido. (Incluye recetas autógrafas de Mociño e Hipólito Ruiz. Aunque el documento no está firmado el contenido no deja lugar a dudas sobre el autor): "Cerca de 19 años ha que trato muy de cerca a D. Martín de Sessé, tiempo a mi parecer bastante para haber podido recoger los fenómenos morales y físicos que juzgo necesarios para determinar sin ligereza la idiosincrasia o temperamento de ese individuo...". 
Traducción.

Moçiño 27 de mayo de 1817.

A Mr. De Candolle en Montpellier.

Mi muy querido amigo. Yo he lamentado siempre la imposibilidad de volver a veros si no quedáis, como se me ha dicho, algún tiempo en Montpellier. Mi amigo Gómez Hermosilla tiene el encargo de todo lo que me concierne e irá a vuestra casa para presentarnos el agradecimiento que debo a vuestra bondad y para tomar a su cuidado mis dibujos; pues tengo una cierta altivez de carácter que no me permite pedir ningún favor a los hombres miserables que ahora pesan sobre mi espíritu.

Yo no pediría el salvoconducto para irme no sé dónde. Pero siempre tendré el reconocimiento que debo a vuestra amistad y a vuestra bondad y no encontraréis nunca ingrato a un viejo en edad y muy niño en la Historia Natural que ama y amará siempre; vuestro constante y agradecido amigo y muy humilde servidor.

J. Mociño ${ }^{83}$.

\section{Comentario.}

Aunque no hay referencia al lugar desde el que escribe, la localización de las cartas segunda y cuarta y la proximidad de las fechas permiten suponer que pudiera hacerlo también desde Alais. Parece claro que la carta se dirige a Montpellier, aunque en ese fecha De Candolle era ya Director del Botánico de Ginebra. El asunto principal, como en la carta anterior, es la recuperación de los dibujos.

De nuevo Mociño muestra su buena relación con un notorio afrancesado, Gómez Hermosilla, que había colaborado intensamente con el gobierno de José Bonaparte - fue jefe de División del Ministerio de Policía-. A pesar de su condición y de que durante su exilio en Francia fue una referencia para otros muchos exiliados, Hermosilla tiene una curiosa trayectoria personal, ya que fue un personaje destacado en todas las etapas políticas, incluyendo las más contradictorias. Había sido protegido de Godoy, luego fue afrancesado llegando a desempeñar una jefatura de división del Ministerio de Policía en José I. Tras su etapa como exiliado regresó a España en 1820 y cuando se reinstaló el absolutismo sirvió como Secretario

вз La firma parece de su puño, no así el texto de la carta, que tiene una letra más regular. 
de Instrucción Pública de Fernando VII en plena Década Ominosa. Fue autor de obras notables sobre historia y lingüística.

\section{$4^{a}$ carta: Transcripción}

A Monsieur.

Monsieur de Candolle.

Directeur du Jardin des Plantes et professeur a l'ecole de Montpellier.

Alais le 17 Juillet 1817.

Mon trés cher ami.

Ma courte vüe (vue?), le défaut de santé et le désir de ne pas vous occasioner inutilment des ports de lettres; m'ont obligé à ne pas vous écrire j'usques á présent, ce que j'ai fais pour trois raisons.

$1^{\circ}$ pour vous renouveller les sentiments de ma vive reconnaissence.

$2^{\circ}$ pour vous recommander le donneur de la présente Mr. Laurent, ex secretaire du depot qui se rends à Montpellier por s'u placer dans un bureau dans une maison de commerce, ou dans une administration en qualité de commis aux écritures.

Vous m'obligerez infinimment Monsieur de l'étayer de tout votre credit pour lui faire obtenir ce qu'il désire, et je ne doute.

.......

nullement de vôtre bon coeur pour lui être utile, je mettrai les services que vous rendrez au rang de ceux dont je vous suis déjà redevable, il le mérite sous tous les rapports, il est à même de se faire distinguer de la foule, tant par ses conaissances en comptabilité que par sa bonne conduite qui jus'ques à ce jour lui á merité l'estime de tous les gens de biens, il ne connaît personne á Montpellier et c'est ce qui me fait prendre la liberté de vous le recommander avec chaleur, bien convaincu d'avant ce qu'il ne pourra que faire honneur a votre bienveillance.

Si vous partez bientôt je vous prie d'avoir la bonté de dire a notre ami Dumail d'avoir soins et de conserver tour mes déssains, si malhereusement je n'ai pas le bonheur de vous trouver à Montpellier lors de mon passage pour l'espagne, si cela est dès ce momment je vous fais mes adieux en vous protextant que je conserverai toute ma vie le souvenir des bontés et des faveurs dont vous m'avez honnorer et que je serai pour toujours.

Votre dévoué serviteur J. Mociño.

P.S. Je vous prie de faire agréer mes respectueuses salutations à Madame votre épouse.

\section{Traducción}

Alais, 17 de julio de 1817 .

Mi muy querido amigo:

Mi corta vista, la falta de salud y el deseo de no ocasionaros inútilmente franqueos de cartas me han obligado a no escribiros hasta ahora que lo hago por tres razones ${ }^{84}: 1^{\circ}$ para renovaros mi agradecimiento.

84 Durante la redacción parece olvidar la tercera, pues aunque invoca tres sólo refiere dos. 
$2^{\circ}$ para recomendaros al portador de la presente Mr. Laurent secretario de despacho que se va a Montpellier para colocarse en la administración de un despacho en una casa de comercio en calidad de encargado de cuentas y correspondencia.

Os quedaré muy obligado en caso de concederle todo vuestro crédito para que consiga lo que desea, y no dudo en absoluto de vuestro buen corazón para serle útil. Yo pondré los servicios que le deis entre los muchos que ya os debo. Él los merece, según todos los informes está en condiciones de destacar tanto por sus conocimientos de contabilidad como por su buena conducta que hasta hoy le ha merecido la estima de todas las gentes de bien; no conoce a nadie en Montpellier y esto es lo que me lleva a tomarme la libertad de recomendarlo con calor, totalmente convencido por anticipado que no podrá más que hacer a vuestra benevolencia.

Si partis pronto os ruego la bondad de decir a nuestro amigo Dumail que cuide y conserve todos mis dibujos, si desgraciadamente yo no tuviera el placer de encontraros en Montpellier cuando pase hacia España. Si esto ocurre desde este momento os doy mi adiós y os prometo que conservaré toda mi vida el recuerdo de las bondades y favores con los que me habéis honrado y que yo tendrá siempre presentes.

Vuestro devoto servidor J. Mociño.

Posdata: Os ruego deis afectuosos saludos a vuestra señora esposa.

\section{Comentario}

Texto con caligrafía muy esmerada, dirigida en el sobreescrito a Mr. De Candolle Director del Jardín de plantas y profesor de la escuela de Montpellier.

La mayor parte del texto se dedica a recomendar al portador sin que exista ninguna otra referencia conocida de esa persona. De nuevo insiste Mociño, como en las dos cartas anteriores, en el interés por asegurarse la recuperación de los dibujos, dando muestras de la amistad y gratitud que le unen a De Candolle.

\section{CONCLUSIONES}

La enorme inversión en toda clase de recursos que supuso la Real Expedición Botánica a Nueva España no ha sido rentable, en términos de prestigio científico o cultural, ni para los participantes ni para quienes la organizaron, ni para la ciencia, dada la escasa difusión de sus resultados. 
En particular, la contribución de Mociño, acrecentada por su papel en la preservación de herbarios, dibujos y manuscritos en condiciones especialmente difíciles, sólo raramente ha encontrado reconocimiento fuera de los ambientes especializados.

Las cartas, objeto principal de este trabajo, contienen referencias a destacados afrancesados con los que Moció se relacionó durante su exilio. Pero, sobre todo, expresan el agradecimiento de Mociño a De Candolle, más allá de su relación personal, ya que suponía el reconocimiento de uno de los más grandes especialistas europeos hacia la inmensidad del esfuerzo realizado y su aportación al conocimiento de las plantas, que contrastaba con el escaso aprecio que había tenido en España. Mociño se muestra también preocupado por la conservación de los documentos, consciente, tanto de su gran valor científico como por servir de aval para su regreso del exilio.

A pesar de las dificultades enumeradas, los fondos documentales de la expedición constituyen un material abundante $y$, en términos generales, en buen estado de conservación. Son lamentables muchas de las circunstancias que les han afectado, pero resultan accesibles, aunque no siempre en el lugar y forma que hubieran deseado quienes participaron en la REBNE. Sobre los fondos se continúa trabajando. Tal vez se consiga algún día publicar el conjunto de la monumental obra. Si eso ocurre, será el mejor tributo a quienes realizaron la Real Expedición Botánica a Nueva España. 